Vol. LXIX 2017

\title{
EXPERIMENTAL METHOD FOR DETERMINING FORCES AT BENDING OF PERFORATED PLATES
}

\author{
PASCU Adrian \\ Professor, Ph.D., Facultyof Engineering / Department of Industrial Machinery and Equipment, "Lucian \\ Blaga"University of Sibiu,Romania,adrian.pascu@ulbsibiu.ro \\ OLEKSIK Mihaela \\ Lecturer, Ph.D., Facultyof Engineering / Department of Industrial Machinery and Equipment, "Lucian \\ Blaga"University of Sibiu, Romania,mihaela.oleksik@ulbsibiu.ro
}

\author{
AVRIGEAN Eugen \\ Associate Professor, Ph.D., Facultyof Engineering / Department of Industrial Machinery and \\ Equipment, "Lucian Blaga"University of Sibiu, Romania,eugen.avrigean@ulbsibiu.ro
}

\begin{abstract}
This paper describes the method of calculating the forces which appear at the bending of perforated plates with holes of different shapes and placed in different patterns, by means of a dynamometric table which uses resistive tensometric transducers (strain gauges). It also describes an instrument for the recording of data from the dynamometric table, a tool created with the aid of the "TestPoint" software which, beneath the data recording, ensures the filtering and statistic processing of data. The obtained results are displayed in comparative graphs for six types of perforated plates, as well as for an unperforated plate.
\end{abstract}

Keywords: perforated plate, V-bending, transducer, strain gauges

\section{Introduction}

The resistive tensometric transducer (Figure 1) consists of base plate 1 and upper plate 2, between which two elastic members 3 are fitted. The base plate has wedges designed for alignment on the compound table, and the upper plate has T-shaped keyways devised for the alignment and fixation of the experimental mold.

The elastic member has been configured so as to allow:

- highlighting the forces studied, with good reproducibility;

- fitting the number of transducers required to build a complete bridge in order to achieve maximum sensitivity, temperature compensation, as well as nonlinearity and hysteresis errors;

- the maximum reduction of the area where voltage distribution is uneven

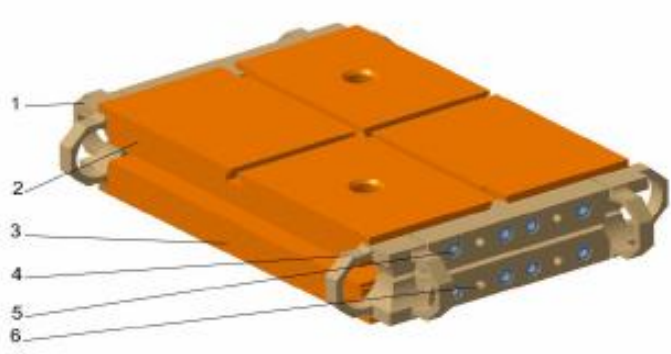

Figure 1 Resistive tensometric transducer

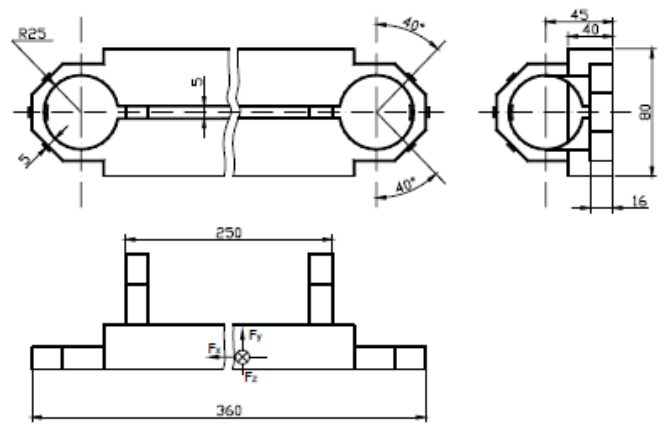

Figure 2 Tensometric transducer layouts 


\section{ACTA UIVERSITATIS CIBINIENSIS - TECHNICAL SERIES}

Vol. LXIX 2017

Bearing in mind specialist literature recommendations, we have opted for a complex elastic member (Figure 2), which allows the highlighting of forces along three directions. The member is ring-shaped, circular on the inside and octagonal on the outside, consisting of two identical halves joined by a stiffener that also provides the foundation.

The stiffener allows the measurement of both static and dynamic forces within the limits imposed by the relatively low fundamental frequency of the ring. The stiffener response is relatively high, with four or even eight resistive tensometric transducers for a single ring.

The tensometric transducers have been bonded at the points where the flexural torques created by the vertical and horizontal forces are cancelled, thus avoiding the mutual influences of the measuring bridges.

\section{Data Acquisition and Processing System}

For data analysis, we have used an assembly consisting of three sub-modules (Figure 3):

- the experimental facility, which in fact directly processes the parts and converts certain mechanical magnitudes into electrical signal via the dynamometric table;

- the data acquisition system;

- the software package that controls the data acquisition and processing system.

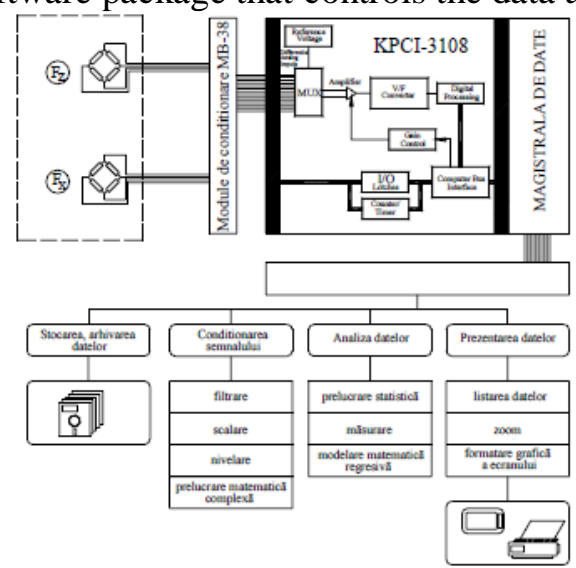

Figure 3 Data acquisition and processing system
The resistive tensometric transducers, which are part of the experimental facility, are connected via the patch panel to the ACjr-12 analogue-to-digital conversion board. They are powered by stabilized electric current. The panel has an eight-channel acquisition capability with a cumulative sampling frequency of up to $10 \mathrm{kHz}$. In low-noise mode, the panel is used with an 18bit resolution, which means $0.024 \%$ at a sampling frequency of $12 \mathrm{~Hz}$ and a signal level of $50 \mathrm{mV}$. The measurement accuracy ensured in this way is of $0.08 \%$. Data is retrieved via the Signalys 3.01 software package.

In addition to archiving and storing the data collected on magnetic storage media, this software allows signal conditioning (filtering, scaling), data analysis (statistical processing, highlighting of minimum and maximum values, elimination of the time variable) and data preparation for the graphical presentation on the monitor, graphics printer or plotter. This data acquisition system has also been used to calibrate the dynamometric table.

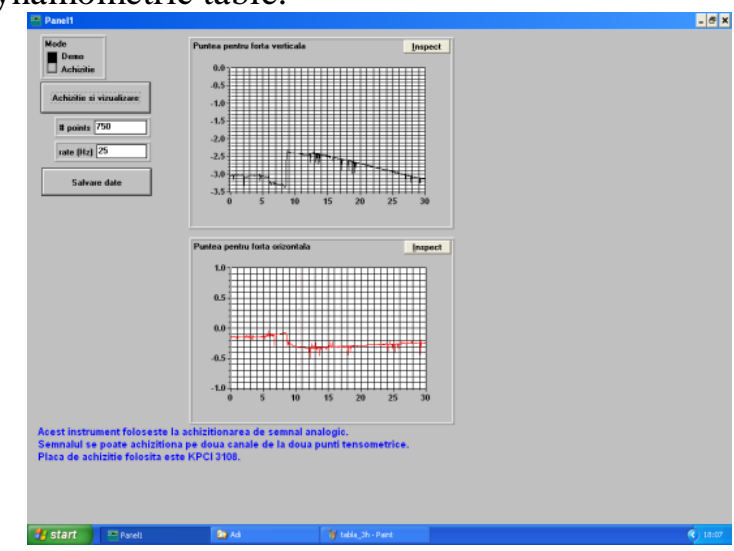

Figure 4 Virtual tool screen used to determine the twodirectional forces occurring at the bending of the perforated plates
The signal acquired from the KPCI 3108 analogue-to-digital board is processed, filtered and saved via a virtual tool created by the author in the TestPoint program, a software package that accompanies the acquisition card and that is dedicated to data acquisition (Figure 4). The tool contains blocks made available to the user by the program, which allow changing the number of channels along which the acquisition is made, the acquisition rate, the total acquisition time, as well as filtering data to eliminate the "noise" inherent to any acquisition and saving data as text files. 


\section{ACTA UIVERSITATIS CIBINIENSIS - TECHNICAL SERIES}

Vol. LXIX 2017

The tool is designed to have four distinct modules: a data acquisition and viewing module, a filtering module, a module for converting electrical magnitudes into mechanical ones, and a module for saving data as text files (ASCII).

\section{Determining the Forces Occurring at the Bending of the Perforated Plates}

After the calibration of the dynamometric table, a V-bending mold has been mounted on it (Figure 5), and the assembly thus obtained has in turn been mounted on the 450 [N] hydraulic press located at the Faculty of Engineering in Sibiu.

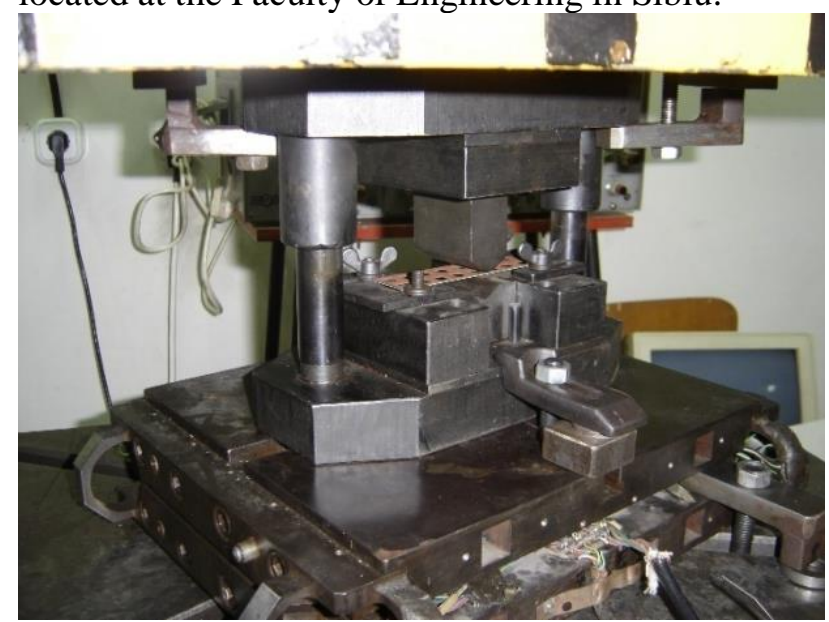

Figure $5 \mathrm{~V}$-bending mould used at the bending of the perforated plates

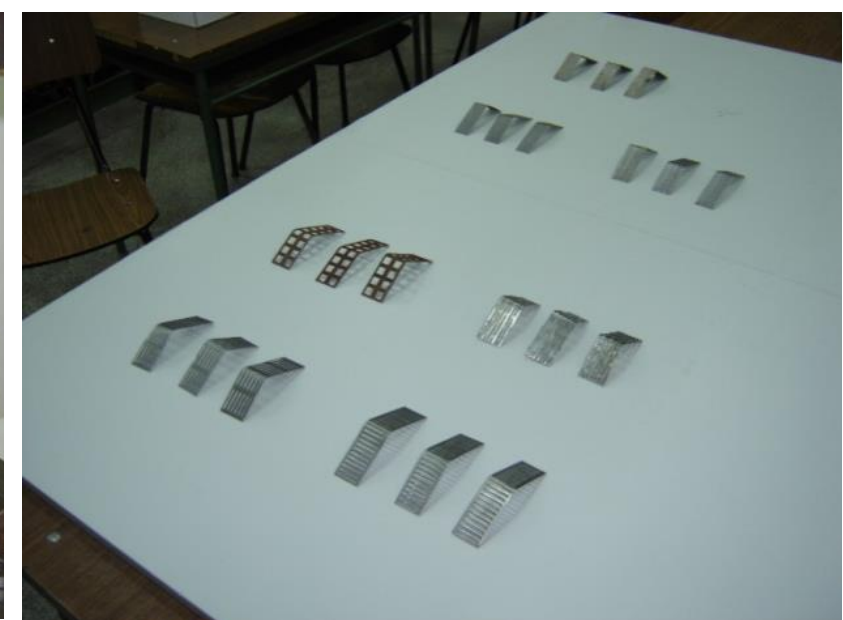

Figure 6 Perforated plate specimens required at bending points

The specimens used for these tests have been made from plate of $1.2 \mathrm{~mm}$ thickness and perforated in various shapes (Figure 6), in order to determine the forces occurring therein depending on the type of perforation. Moreover, the forces have been determined on a direction perpendicular to the plane of the dynamometric table (hereinafter referred to as vertical direction) and on a direction parallel to the long side of the specimens (hereinafter referred to as the horizontal direction) as well as for a plate of the same thickness, but not perforated.

Figures 7 to 20 show the variation graphs of forces on the horizontal and vertical directions that occur during the bending process for each type of perforated plate studied. Table 1 also shows the maximum values in the two-force mode.

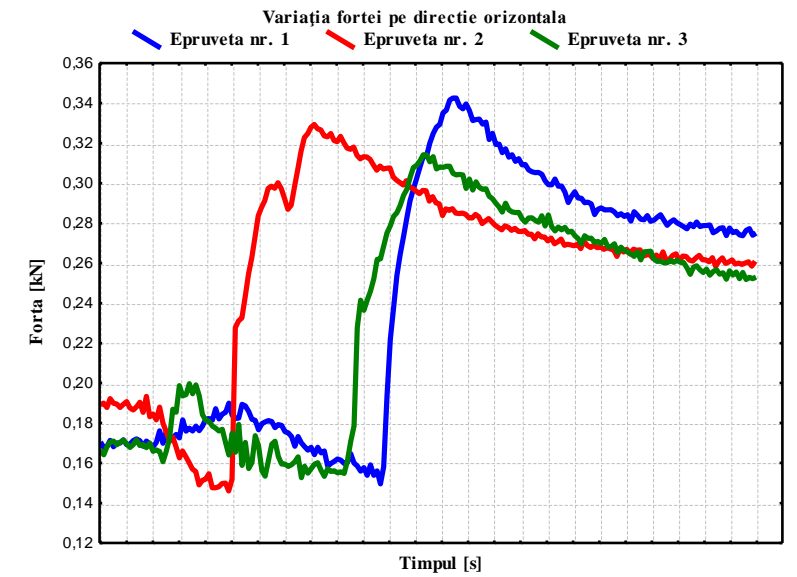

Figure 7 Variation of horizontal force for three specimens with circular holes of diameter $\mathrm{d}=1 \mathrm{~mm}$

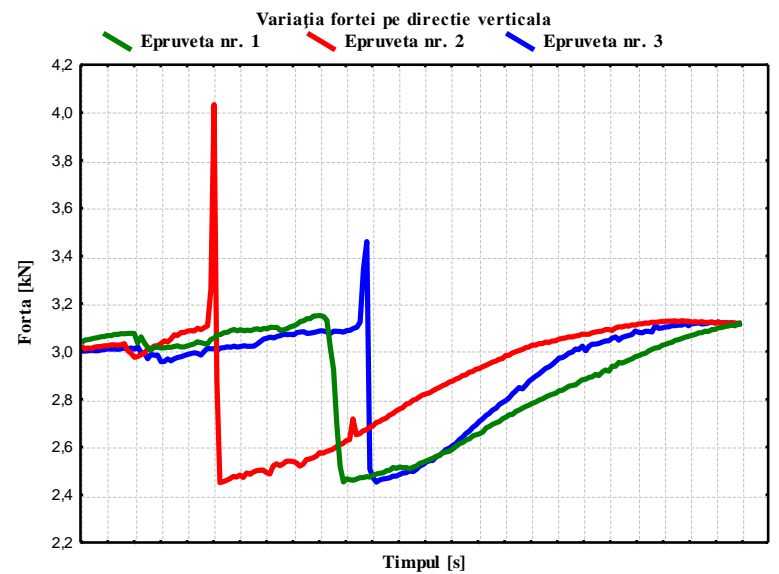

Figure 8 Variation of vertical force for three specimens with circular holes of diameter $\mathrm{d}=1 \mathrm{~mm}$ 


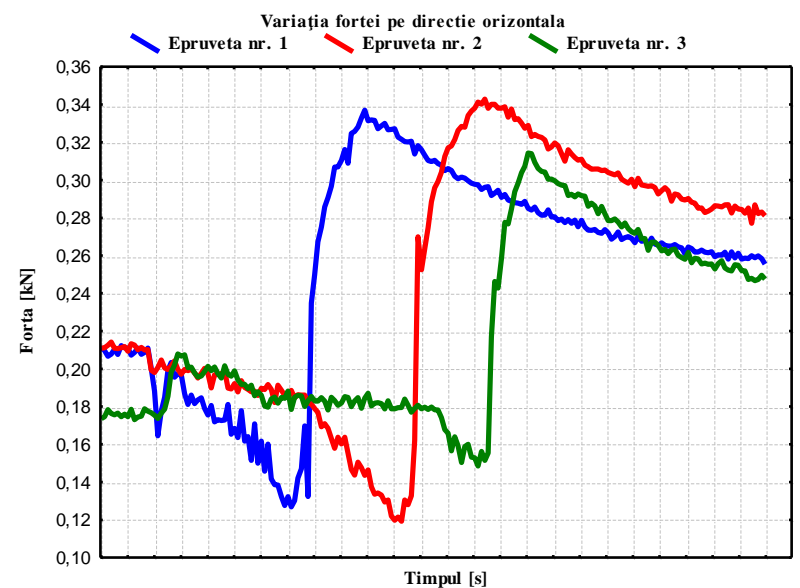

Figure 9 Variation of horizontal force for three specimens with circular holes of diameter $d=3.5 \mathrm{~mm}$

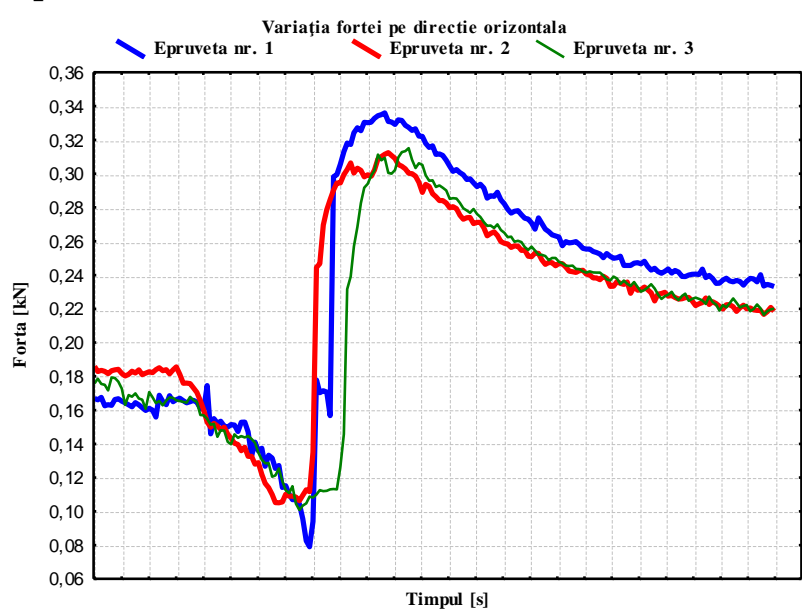

Figure 11 Variation of horizontal force for three specimens with square holes of side $\ell=10 \mathrm{~mm}$

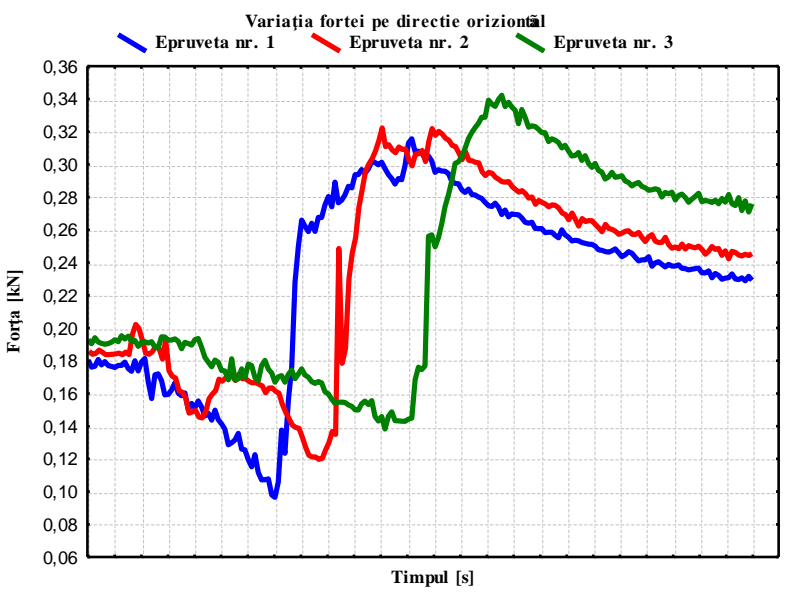

Figure 13 Variation of horizontal force for three specimens with $24.2 \times 2$ wedge keyway holes ( $Z$-shaped perforation) arranged longitudinally

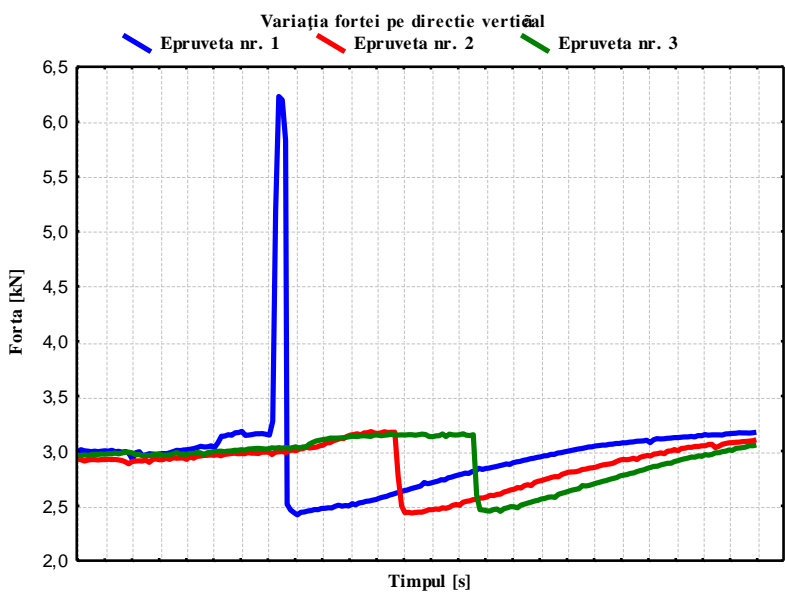

Figure 10 Variation of vertical force for three specimens with circular holes of diameter $\mathbf{d}=\mathbf{3 . 5} \mathrm{mm}$

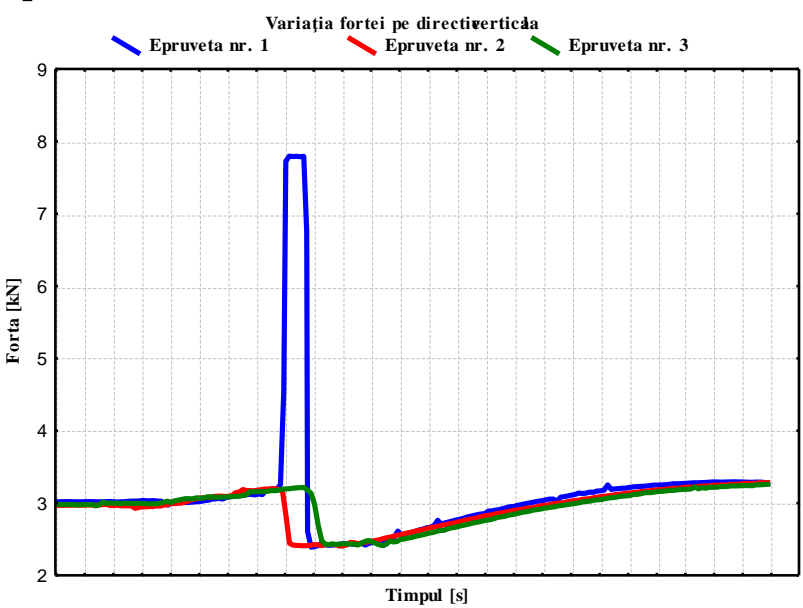

Figure 12 Variation of vertical force for three specimens with square holes of side $\ell=10 \mathrm{~mm}$

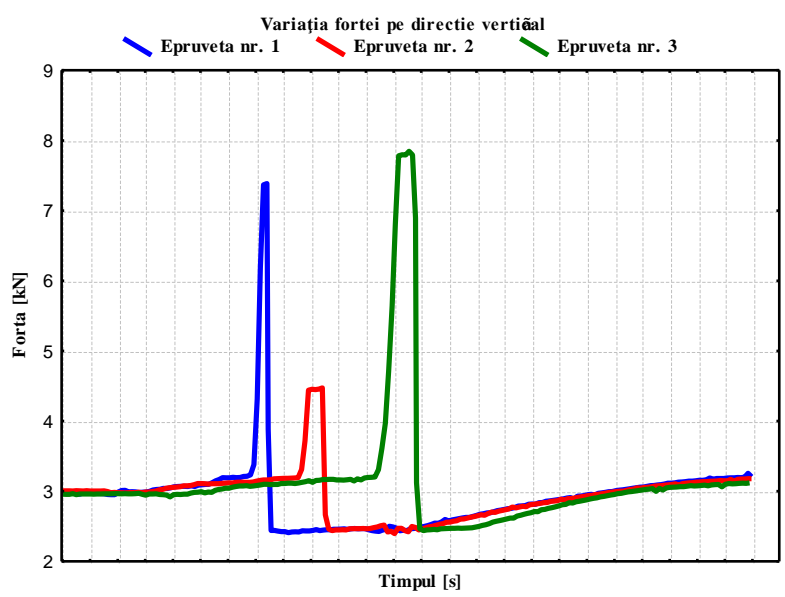

Figure 14 Variation of vertical force for three specimens with $24.2 \times 2$ wedge keyway holes (Z-shaped perforation) arranged longitudinally 


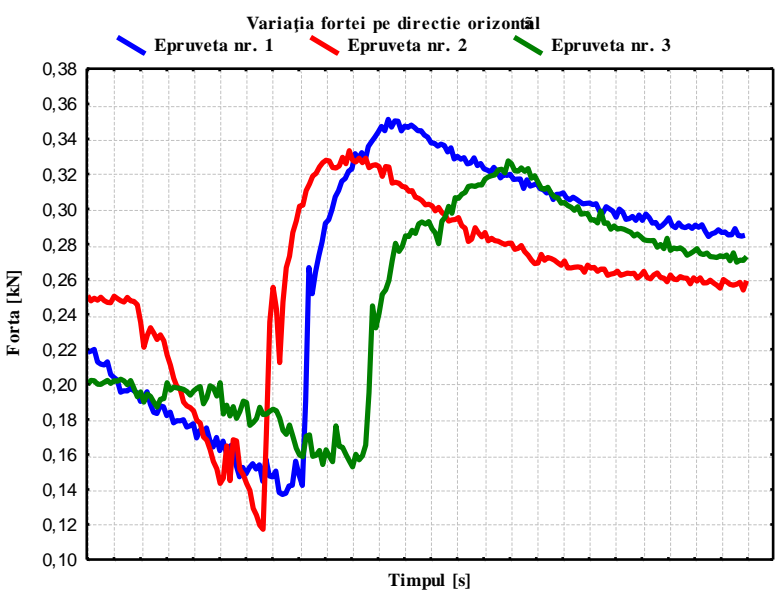

Figure 15 Variation of horizontal force for three specimens with $24.2 \times 2$ wedge keyway holes (Apshaped perforation) arranged longitudinally

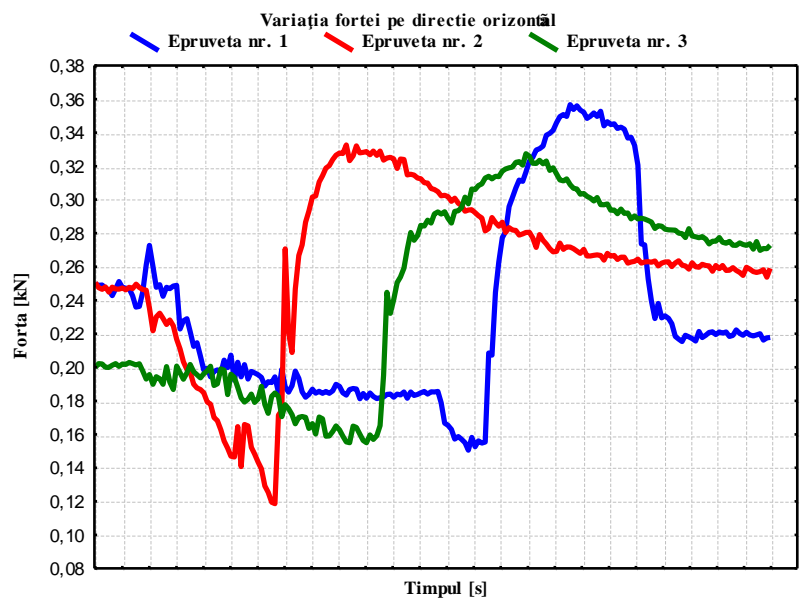

Figure 17 Variation of horizontal force for three specimens with $24.2 \times 2$ wedge keyway holes (Apshaped perforation) arranged transversely

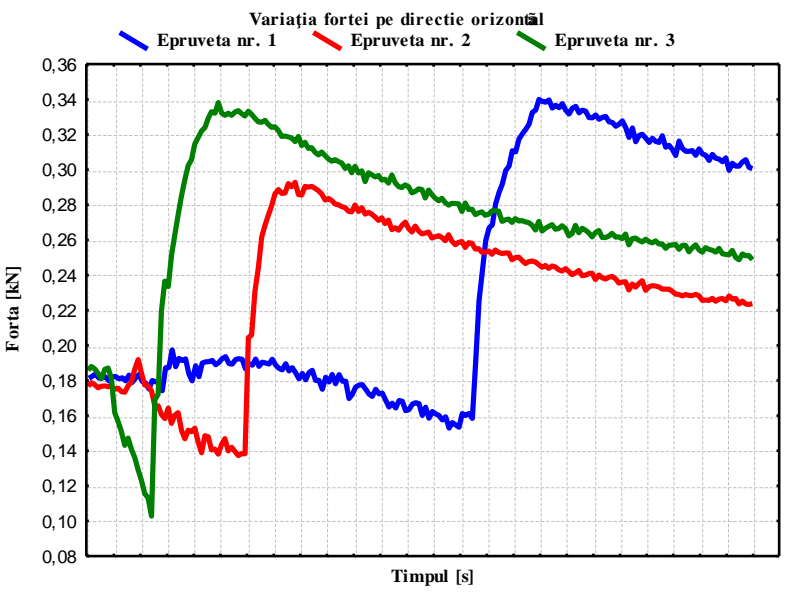

Figure 19 Variation of horizontal force for three plate specimens of thickness $\mathrm{g}=\mathbf{1 . 2}$ with no perforations

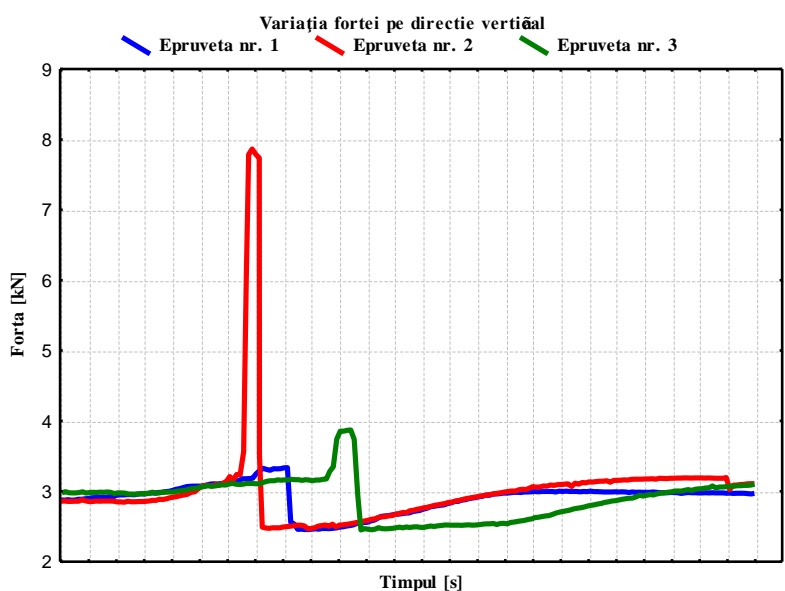

Figure 16 Variation of vertical force for three specimens with $24.2 \times 2$ wedge keyway holes (Apshaped perforation) arranged longitudinally

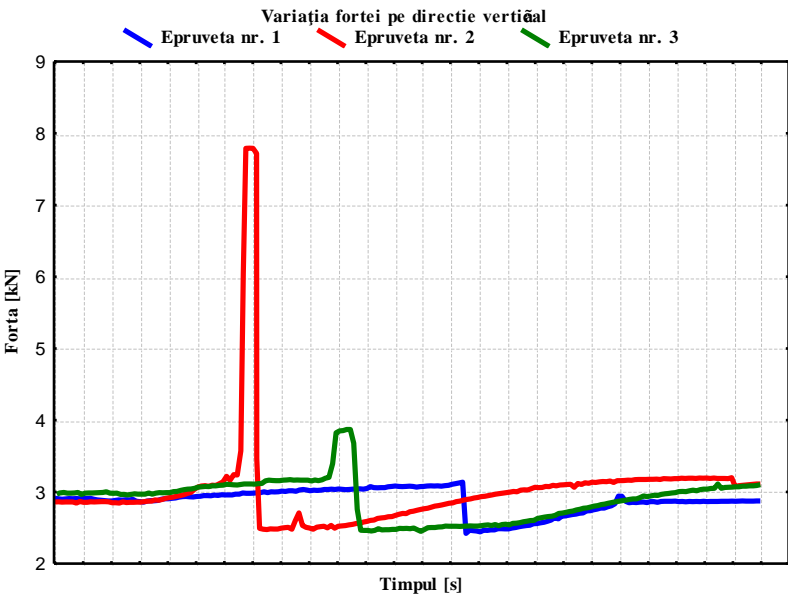

Figure 18 Variation of vertical force for three specimens with $24.2 \times 2$ wedge keyway holes (Apshaped perforation) arranged transversely

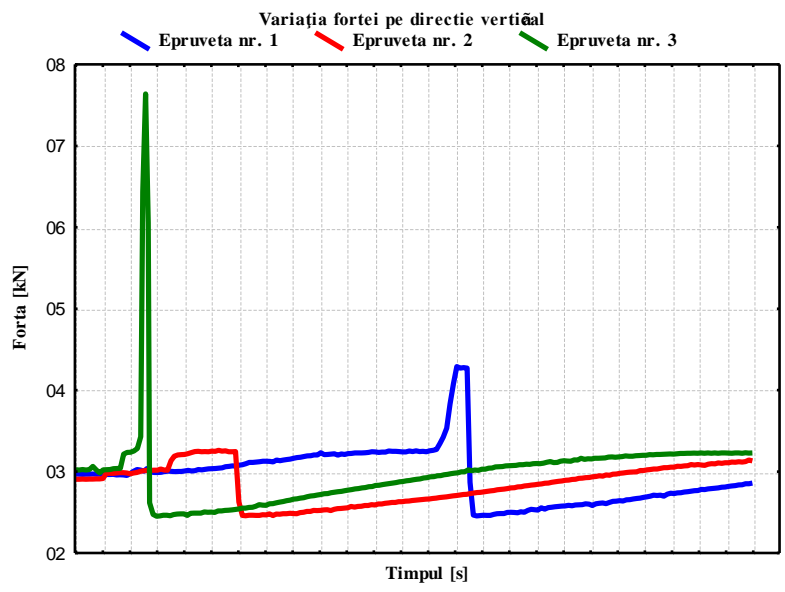

Figure 20 Variation of vertical force for three plate specimens of thickness $\mathrm{g}=\mathbf{1 . 2}$ with no perforations

\section{Conclusions}




\section{ACTA UIVERSITATIS CIBINIENSIS - TECHNICAL SERIES}

Vol. LXIX 2017

After analyzing the graphs above, we have notices the following:

Along the horizontal direction, the force is approximately $10 \%$ of the force along the vertical direction, in all 7 cases studied;

The force along the horizontal direction slightly decreases at first, then increases quite rapidly during the stroke of the punch, following which, at the time of the withdrawal of the punch, it again has a slight tendency to decrease; at the same time, we have noticed that the horizontal force has values that are very close for all the specimens, which is why we can state that it is influenced neither by the perforation type nor by the hole size, and what is more, it is sensitively equal to the horizontal force of the non-perforated plate; The vertical force also has a slight tendency to decrease at the beginning of the bending process, following which its value increases much faster and to a higher value than the horizontal force, then decreases just as fast, and, towards the end of the bending process, it again has a very slight upward trend. As regards a comparison between the value of this force on perforated plates and the value of the same force on a non-perforated plate, we have noticed an increase of about $50 \%$ in this force in the latter case provided that the perforated surface is of $25 \%$.

Table 1 Results of experimental tests

\begin{tabular}{|c|c|c|c|c|c|}
\hline $\begin{array}{l}\text { Curr } \\
\text { ent } \\
\text { no. }\end{array}$ & $\begin{array}{c}\text { Perforation } \\
\text { type }\end{array}$ & $\begin{array}{c}\text { Plate } \\
\text { thickness } \\
\underset{\text { g }}{[\mathrm{mm}]}\end{array}$ & $\begin{array}{c}\text { Hole } \\
\text { diameter } \\
\text { d } \\
{[\mathrm{mm}]}\end{array}$ & $\begin{array}{c}\text { Maximum force } \\
\text { along horizontal } \\
\text { direction } \\
F_{H \max } \\
{[\mathrm{kN}]}\end{array}$ & $\begin{array}{c}\text { Maximum force } \\
\text { along vertical } \\
\text { direction } \\
F_{\text {Vmax }} \\
{[\mathrm{kN}]}\end{array}$ \\
\hline 1. & \multirow{3}{*}{ circular "Z" } & \multirow{3}{*}{1.2} & \multirow{3}{*}{1} & 0.34363 & 3.48938 \\
\hline 2. & & & & 0.33203 & 4.05243 \\
\hline 3. & & & & 0.31586 & 3.15796 \\
\hline \multicolumn{4}{|c|}{ Arithmetic mean } & 0.33051 & 3.56659 \\
\hline 4. & \multirow{3}{*}{ circular "Z" } & \multirow{3}{*}{1.2} & \multirow{3}{*}{3.5} & 0.33997 & 3.84460 \\
\hline 5. & & & & 0.34424 & 3.17841 \\
\hline 6. & & & & 0.31403 & 3.16650 \\
\hline \multicolumn{4}{|c|}{ Arithmetic mean } & 0.33275 & 3.39650 \\
\hline 7. & \multirow{3}{*}{ square "Ap" } & \multirow{3}{*}{1.2} & \multirow{3}{*}{10} & 0.33722 & 7.82776 \\
\hline 8. & & & & 0.31433 & 3.28552 \\
\hline 9. & & & & 0.31616 & 3.26691 \\
\hline \multicolumn{4}{|c|}{ Arithmetic mean } & 0.32257 & 4.79339 \\
\hline 10. & \multirow{3}{*}{$\begin{array}{l}\text { longitudinal Z- } \\
\text { shaped keyway }\end{array}$} & \multirow{3}{*}{1.2} & \multirow{3}{*}{$24.2 \times 2$} & 0.31586 & 7.46765 \\
\hline 11. & & & & 0.32227 & 4.45770 \\
\hline 12. & & & & 0.34302 & 7.85522 \\
\hline \multicolumn{4}{|c|}{ Arithmetic mean } & 0.32705 & 6.59352 \\
\hline 13. & \multirow{3}{*}{$\begin{array}{l}\text { transversal Ap- } \\
\text { shaped keyway }\end{array}$} & \multirow{3}{*}{1.2} & \multirow{3}{*}{$24.2 \times 2$} & 0.35248 & 3.33832 \\
\hline 14. & & & & 0.33295 & 7.79694 \\
\hline 15. & & & & 0.32745 & 3.87573 \\
\hline \multicolumn{4}{|c|}{ Arithmetic mean } & 0.33946 & 4.93581 \\
\hline 16. & \multirow{3}{*}{$\begin{array}{l}\text { longitudinal Ap- } \\
\text { shaped keyway }\end{array}$} & \multirow{3}{*}{1.2} & \multirow{3}{*}{$24.2 \times 2$} & 0.35797 & 3.13477 \\
\hline 17. & & & & 0.33295 & 7.79694 \\
\hline 18. & & & & 0.32745 & 3.87573 \\
\hline \multicolumn{4}{|c|}{ Arithmetic mean } & 0.33945 & 4.93581 \\
\hline 19. & \multirow{3}{*}{$\begin{array}{l}\text { Non-perforated } \\
\text { plate }\end{array}$} & \multirow{3}{*}{1.2} & \multirow{4}{*}{---} & 0.34088 & 4.30328 \\
\hline 20. & & & & 0.29388 & 3.26324 \\
\hline 21. & & & & 0.33813 & 7.66724 \\
\hline \multicolumn{3}{|c|}{ Arithmetic mean } & & 0.32429 & 5.07792 \\
\hline
\end{tabular}


ACTA UIVERSITATIS CIBINIENSIS - TECHNICAL SERIES

Vol. LXIX

2017

\section{References}

1. Buzdugan, Ghe., Blumenfeld, M., Tensometrie electrică rezistivă, Editura Tehnică, București,1966.

2. Pascu, A., Curtu, I., Captor electrotensometric pentru măsurarea forţelor la încovoierea plăcilor perforate, $A$ 4a Conferinţă de Dinamica Maşinilor, Braşov, 2005, pag. 339-344.

3. Pascu, A., Oleksik, V., Curtu, I., Avrigean, E., Determination of Forces at the Bending of Perforated Plates with Slotted Holes through Experimental and FEM. The 20 th DAAAM International World Symposium, 25-28 November 2009, Vienna, Austria, ISSN 1726-9679, pp. 799-800, (2009).

4. Peride, N., Iliescu, N., Tehnici tensometrice, Editura Politehnica Press, Bucureşti, 2003.

5. Savin, G.N., Concentraţia tensiunilor in jurul golurilor, Goztehizdat, 1956.

6. Savin, G.N., Distribuţia tensiunilor in jurul golurilor, Kiev, 1968.

7. *** Test Point user's guide. Quick start. Vol. 1, 1995.

8. *** Test Point user's guide. Techniques reference. Vol. 2, 1995. 